\title{
Apontamentos sobre a noção de conhecimento na modernidade e o mundo vivido
}

\section{Notes on the notion of knowledge in modernity and the lived world}

https://doi.org/10.34112/2317-0972a2021V39n82p43-54

\author{
SANDRA Aparecida RiscaL ${ }^{1}$ \\ José ReINALDo RISCAL ${ }^{2}$
}

RESUMO: Este artigo tem como objetivo apresentar algumas reflexões e apontamentos sobre a concepção de conhecimento, segundo a ciência moderna e o abandono da concepção de mundo vivido e de experiência de vida que essa concepção determinou. Pretende-se relacionar essas concepções de conhecimento e mundo vivido com a natureza do ensino tal como vem sendo praticado nas escolas, particularmente no Brasil, após a Constituição de 1988. Pretende-se, ainda, avaliar em que medida a prevalência da concepção de conhecimento, segundo os padrões da modernidade, pode entrar em conflito com o mundo vivido, tal como é concebido pelos alunos.

Palavras-chave: Conhecimento; saber; mundo vivido; relação com o saber.

ABSTRACT: This article aims to present some reflections and notes on the concept of knowledge, according to modern science and the abandonment of the concept of lived world and life experience that this concept determined. It is intended to relate these conceptions of knowledge and the world experienced with the nature of teaching as it has been practiced in schools, particularly in Brazil, after the 1988 constitution. It is also intended to assess, to

1. Universidade Federal de São Carlos - UFSCar - São Paulo - Brasil.

2. Universidade Federal de São Carlos - UFSCar - São Paulo - Brasil. 
what extent, the prevalence of conception knowledge, according to the standards of modernity, may conflict with the world experienced, as it is conceived by students.

KEYWORD: Knowledge; lived worl; relationship with knowledge.

\section{INTRODUÇÃO}

\section{O CONCEITO DE CONHECIMENTO SEGUNDO A CIÊNCIA MODERNA}

O Novo Dicionário Aurélio da Língua Portuguesa (1986), apresenta várias acepções para o vocábulo "conhecimento": "1. Ato ou efeito de conhecer; 2. Ideia, noção; 3. Informação, notícia, ciência; 4. Prática da vida; experiência; 5. Discernimento, critério, apreciação; 6. Consciência de si mesmo; acordo; 7. Pessoa com quem travamos relações”. A acepção 11 abrange a filosofia: no sentido mais amplo, atributo geral que têm os seres vivos de reagir ativamente ao mundo circundante, na medida de sua organização biológica e no sentido de sua sobrevivência (FERREIRA, 1986, p. 454).

Também o Dicionário Houaiss da Língua Portuguesa apresenta várias acepções para o vocábulo "conhecimento". Consideraremos aqui as principais, além do ato ou efeito de conhecer:

1. o ato ou a atividade de conhecer, realizada por meio da razão e/ou da experiência; 1.1. ato ou efeito de apreender intelectualmente, de perceber um fato ou uma verdade, cognição, percepção; 1.2. fato, estado ou condição de compreender; entendimento; 2.1. domínio teórico ou prático, de um assunto, uma arte, uma ciência, uma técnica, etc.”.

$\mathrm{Na}$ acepção relativa à filosofia encontramos os seguintes significados:

16. Procedimento compreensivo por meio do qual o pensamento captura representativamente um objeto qualquer, utilizando recursos investigativos, dessemelhantes - intuição, contemplação, classificação, mensuração, analogia, experimentação, observação empírica, que, variáveis historicamente, dependem dos paradigmas filosóficos e científico que em cada caso lhes deram origem. (HOUAISS; VILLAR; FRANCO, 2001, p. 802).

Uma breve análise dos conteúdos dos verbetes dos dois principais dicionários da língua portuguesa permite que se verifique a riqueza e, muitas vezes, as ambiguidades das diferentes acepções do vocábulo "conhecimento". Em ambos os 
casos, os significados não excluem os domínios práticos. Podemos considerar que as acepções apresentadas pelo Dicionário Houaiss (2001) privilegiam os aspectos mais acadêmicos, acentuando que o conhecimento é o ato realizado por meio da razão e constitui uma apreensão intelectual. Também admitem os significados de compreensão e entendimento. Já o Dicionário Aurélio salienta acepções mais próximas do senso comum, tais como prática da vida, experiência, incluindo até os significados de informação e notícia. Mas a maior diferença encontra-se na acepção filosófica. Enquanto o Dicionário Houaiss (2001) privilegia concepções próprias da história da filosofia e da ciência moderna, o Dicionário Aurélio (1986) opta por uma definição mais geral: "atributo geral que têm os seres vivos de reagir ativamente ao mundo circundante". Trata-se de uma concepção de conhecimento que prioriza a vida ativa e a interação dos seres vivos com o mundo em que vivem.

Os dois dicionários parecem capturar, com flagrante clareza, a ambiguidade do conceito de conhecimento, permitindo que se possam considerar formas de conhecimento que não se podem reduzir à vetustez da ciência moderna. O Dicionário Aurélio parece deixar vislumbrar conotações que tinham sido excluídas de nossa concepção oficial de conhecimento, mas que ainda frequentam, de forma viva e exuberante, nosso senso comum. $\mathrm{O}$ senso comum pode ser concebido como um processo de representação, leitura e interpretação do mundo, próprio à população não letrada. Mais próximo da vida cotidiana, o senso comum, em uma comunidade, constitui seu campo cultural e fornece os elementos para a organização da visão de mundo de todos os seus membros.

A Educação, por sua vez, tem primado pela aproximação, cada vez maior, entre conhecimento científico e conteúdos educacionais, excluindo de suas formas de conhecimento aquelas próprias ao mundo vivido ou ao senso comum.

Em verbete do Diccionario de las Ciencias de la Educación (1995), editado na Espanha, Lorenzo García Huerta define conhecimento, na acepção pedagógica do termo, como o saber ou o conjunto dos saberes que constituem o "currículo de cada uma das ciências" (GARCÍA HUERTA, 1995, p. 308). Esta definição do dicionário espanhol atesta a relação de proximidade entre conhecimento científico e educação na modernidade. Nascida no século XIX, a Pedagogia, tal como a conhecemos, floresce em meio à franca ascensão da ciência moderna e das Ciências da Educação. 
CONHECIMENTO, CIÊNCIA, EDUCAÇÃo E VIDA

Conhecimento e educação são dois campos que, embora separados historicamente, são constituintes de um mesmo processo original de construção humana e como tais estão inseridos na vida social e coletiva. A ciência, ao longo do tempo, acabou por separar-se da vida, relacionando-se com um projeto que gradualmente se distanciou do processo de humanização pretendido em sua origem. A ciência constitui uma das mais importantes construções da história humana e, portanto, não deveria dela afastar-se. Todavia, o projeto que levou à concepção científica na modernidade apresentou-se cada vez mais impessoal, objetivo, neutro e desapaixonado, revelando-se ambíguo em relação a sua origem, metodologia e concepção social. Como resultado, o desenvolvimento técnico e científico parece não ter contribuído significativamente para a liberdade e para o fim da dominação dos homens sobre outros homens, mas ter servido, principalmente, para ratificar essa dominação. Considerando-se que o projeto científico moderno foi erigido por meio de um processo de dominação da natureza, seus instrumentos de dominação também se tornaram eficientes para o controle e o disciplinamento da própria humanidade, especialmente por meio da burocratização da educação e do trabalho.

Uma das primeiras definições sobre o que é conhecimento pode ser encontrada no diálogo de Platão, denominado Teeteto (2020). Segundo Platão, todo conhecimento é uma crença justificada por meio de evidências adequadas. Platão separa, assim, a mera crença, que constituiria o senso comum, do conhecimento verdadeiro, aquele que se caracterizaria por apresentar evidências adequadas como garantia de sua veracidade.

Aristóteles (1978), por sua vez, no livro I da Metafísica, considera que todo conhecimento nasce da experiência no mundo, mas acrescenta que esse seria apenas o início do processo de conhecimento, que deveria ser submetido a critérios racionais capazes de determinar as suas causas.

A história da filosofia e a epistemologia - disciplina que, definida de forma geral, dedica-se ao estudo do conhecimento -, têm sido povoadas, ao longo dos séculos, por pensadores que desenvolveram as doutrinas platônicas ou aristotélicas, ou discordaram de ambas e apresentaram seus próprios sistemas de conhecimento.

A ciência moderna, cujo nascimento pode ser datado no século $\mathrm{XV}$, teve como fundamento as concepções de Francis Bacon, para quem "saber é poder" e, posteriormente, os sistemas de Galileu e Newton, entre outros pensadores. O principal sustentáculo da ciência moderna é a concepção segundo a qual o conhecimento válido 
é aquele que, considerando a observação impessoal, objetiva e neutra de um experimento e a sua repetição, permite formular leis gerais e invariáveis. Essa concepção constitui o alicerce sobre o qual se edificou toda a ciência moderna, possibilitando o desenvolvimento das técnicas que levaram para mais além o adágio de Bacon: "saber é poder". Saber é poder, e poder é dominação. A ciência tinha como objetivo dominar a natureza e, por meio do desenvolvimento técnico, dominou também os homens.

Em particular, o processo de observação e experimentação que caracteriza boa parte dos métodos científicos introduziu formas de pensar sobre esses conceitos que os afastaram do campo do mundo tal como ele é vivido. A concepção de observação como um procedimento impessoal e objetivo, durante o qual o sujeito é mero receptor neutro, contribuiu para que a ciência se distanciasse da vida cotidiana. E, doravante, o homem de ciência passou a frequentar laboratórios e gabinetes universitários, produzindo um conhecimento que só pode ser considerado como tal, mediante a criteriosa inspeção de seus próprios pares. Criou-se, assim, um grande abismo entre o saber cientifico acadêmico e intelectualizado e o saber do mundo vivido, aprendido pelas pessoas durante as suas relações sociais e culturais cotidianas.

A concepção tradicional da ciência, que toma a observação como um processo passivo, durante o qual o observador apenas recebe informações do meio, há muito foi contraditada. Desde Kant, pensador do final do século XIX, o observador deixou de ser concebido como um receptáculo inativo em relação àquilo que observa. A observação é uma das mais importantes formas do agir humano e, diferentemente de como é frequentemente concebida, durante qualquer observação, nosso entendimento está ativo, como atesta a psicologia cognitiva. Todos os nossos conhecimentos são construídos de forma ativa e toda observação passa por um processo de mediação que a relaciona com as estruturas de conhecimento que já possuímos. Há, nesse sentido, uma reorganização de nossas concepções preexistentes, resultantes de nosso viver no mundo, que interage com o que é observado. Como não é passiva, a observação reorganiza continuamente a nossa visão de mundo subjetivamente construída. Isso significa que há no sujeito uma atividade que organiza a observação, articulando-a com as noções que ele já possuía anteriormente (FOUREZ, 1995).

A observação apresenta-se, assim, como um constante processo de estruturação e reestruturação das representações do mundo. São as relações com o mundo e com os outros que, observadas, fornecem os elementos para que cada um situe a si e aos demais na esfera da vida. Tomada nesse sentido, a observação adquire outro 
significado, que a afasta da concepção puramente teórica e abstrata da ciência acadêmica, apresentando novas dimensões e possibilidades de reflexão.

Também o conceito de experiência, tal como concebido na ciência acadêmica, apresenta conotações diferentes, quando pensado em relação à esfera da vida. A experiência científica carrega consigo os mesmos atributos da observação: a impessoalidade, a objetividade e a neutralidade. Um experimento científico deve garantir a total ausência de considerações subjetivas e deve pautar-se pelo afastamento total de qualquer influência do observador.

Não obstante, quando tratamos da experiência, no mundo da vida, consideramos as relações que subjetivamente imprimiram novas concepções de mundo e de agir em relação a ele. Experimentar é viver novas possibilidades de estar no mundo e de vivenciar diferentes formas de conceber a si e aos outros.

Hannah Arendt, uma das mais importantes pensadoras alemãs do século XX, criticou continuamente, em sua vasta obra, a dissociação produzida na modernidade entre a ciência e a vida. Revalorizando o senso comum, renegado pela ciência por não atender às exigências de impessoalidade, objetividade e neutralidade, Arendt (2015) considera que o senso comum é a única coisa partilhada por todos que nos permite considerar que vivemos em um mundo em comum.

O único atributo do mundo que nos permite avaliar a sua realidade é o fato de ser comum a todos nós; e, se o senso comum tem uma posição tão alta na hierarquia das qualidades políticas, é que é o único fator que ajusta à realidade global de nossos cinco sentidos estritamente individuais e os dados rigorosamente particulares que eles registram. Graças ao senso comum, é possível saber que as percepções sensoriais mostram a realidade, e não são meras irritações de nossos nervos nem sensações de reação de nosso corpo. (ARENDT, 2015, p. 221).

É, portanto, a nossa experiência vivida e o sentimento de viver em um mundo em comum que permitem a todos nós considerarmo-nos pertencentes a um mesmo mundo e partilhar desse mundo de forma mais humana.

Arendt (2015, p. 31) observa que o mundo no qual todos vivemos não existiria sem a atividade dos homens que o produzem. Afinal, "nenhuma vida humana, nem mesmo a vida do eremita em meio à natureza selvagem, é possível sem um mundo que, direta ou indiretamente, testemunhe a presença de outros seres humanos”. 
É, portanto, no convívio do mundo, com os demais homens, que cada um pode reconhecer a si como homem, pois é por meio do reconhecimento do outro que cada homem se humaniza, isto é, compreende-se como humano. É, portanto, a vida em comum, a atividade entre os homens, o conhecimento que constroem em comum, que humanizam o homem, isto é, o que os torna humanos.

Os homens não podem, para Arendt (2015), dar-se ao luxo de conferir primariamente sua atenção às vidas individuais. E muito menos a ciência deveria isolar-se de sua tarefa humanizadora. Enclausurada e isolada do mundo, a ciência moderna teria se apartado dos homens e possibilitado o crescente processo de tecnicização que favoreceu a dominação da burocracia sobre a vida mundana.

\section{CONHECIMENTO, SABER E EDUCAÇÃO}

A educação, tal como vem sendo compreendida, pelos menos desde os últimos quatrocentos anos, constituiu-se como um campo no qual predominou o conhecimento no sentido exclusivamente científico e acadêmico. A observação e a experiência foram identificadas, nos tratados educacionais e pedagógicos, com as concepções da esfera da ciência. $\mathrm{O}$ mundo da vida e os saberes cotidianos foram abolidos das escolas como anticientíficos, e o ensino passou a dedicar-se exclusivamente ao conhecimento produzido pelos cientistas em seus gabinetes e academias - impessoal, neutro e sem vida. Entretanto, a vida em comum, a atividade entre os homens, o conhecimento que constroem conjuntamente é que humanizam o homem, isto é, o que os torna humanos.

Nunca essa dissociação entre conhecimento científico e vida foi tão dramática quanto na atualidade e nunca seus efeitos foram tão perniciosos para a educação quanto nos dias de hoje. Desde a Constituição de 1988 o projeto de universalização da educação básica tem levado à escola contingentes de alunos que antes estavam completamente à margem de qualquer processo de ensino. $\mathrm{O}$ direito à Educação, concebido como um direito subjetivo de todo o cidadão, obrigou as escolas a abrirem seus portões à entrada de sujeitos que antes eram por ela eliminados.

Ocorre que os professores e os cursos de Pedagogia que os formam permanecem, até os dias de hoje, com a mesma concepção de ensino das décadas que precederam as inovações democráticas da Constituição de 1988. Corações e mentes de professores, gestores e até mesmo de pais permanecem estacionados na Educação das décadas de 1950 e 1960, concebidas como uma espécie de Idade de Ouro da Educação. Naqueles períodos, diga-se de passagem, a escola era frequentada por 
alunos de classe média e classe média alta, com pais frequentemente letrados. Exigiam-se disciplina e bom comportamento, na escola e em casa, e o uso de formas de punição corporal era não apenas aceito, mas muitas vezes incentivado pelos pais.

Um saudosismo em relação àquela escola, cujo retorno alguns desejam ver, nutre a insatisfação com as condições das escolas atuais - em especial na escola pública, cujos docentes, nas décadas de 1950 e 1960, acreditavam pertencer a uma elite. Essa nostalgia é ainda maior nas escolas de periferia, nas quais os docentes parecem se recusar a compreender que seus alunos não são mais os mesmos. Além disso, o Estatuto da Criança e do Adolescente, de 1990, aboliu os instrumentos de punição corporal, por parte tanto de pais quanto de professores. Apegados a uma concepção tradicional de ensino, muitos professores não conseguiram realizar a transição para uma escola mais democratizada, frequentada não mais por uma elite, mas por toda a população. Aqueles que eram marginalizados, excluídos e punidos têm, agora, o direito legítimo de frequentar as escolas. E o desafio agora é: o que fazer com esses alunos?

Também os alunos parecem preocupar-se com o problema - afinal, boa parte deles não consegue encontrar na escola nenhuma finalidade para sua vida, não vê nela uma via de acesso para uma vida melhor ou um caminho para um futuro bom emprego (RISCAL, 2016). A escola lhes parece ser um caminho difícil, que exige muita disciplina e paciência, sem que eles compreendam o porquê do que estão fazendo. Principalmente nas escolas de periferia, o que é ensinado está frequentemente muito distante das vidas dos alunos e não tem para essas crianças significado nem sentido, porque o conhecimento científico, que constitui a base dos currículos escolares, afastou-se de forma abismal do mundo vivido.

O tipo de ensino oferecido nas salas de aula tem como fundamento o conhecimento científico, impessoal, neutro, objetivo e desapaixonado. As avaliações seguem a mesma concepção e assumem um caráter punitivo e classificatório. Além disso, os valores propagados pela escola são muito pouco vinculados à vida e ao cotidiano do aluno, que, antes de ser estudante, vive em uma comunidade, com regras e vias de ascensão social próprias (RISCAL, 2016). Trata-se de uma cultura local e própria, que, frequentemente, nada tem em comum com aquela difundida pela escola.

Não é de causar espanto que a escola, mesmo com constantes debates sobre a sua democratização e inumeráveis reformas ou propostas de mudanças, permaneça produzindo a exclusão social. Fala-se em fracasso escolar. Muito se critica o uso dessa expressão. Mas o termo, se bem entendido, descreve a situação de nossa educação: há um fracasso escolar porque as escolas fracassam, não os alunos. A propósito, as 
críticas do pensador francês, Bernard Charlot (2000) ao conceito de fracasso são muito pertinentes: ele considera que a concepção de "fracasso", como uma indicação de que existe uma carência do aluno supostamente fracassado, induz a um processo educacional excludente e acaba por reproduzir os problemas tradicionais da escola.

\section{Bernard CHARLot E A RelaÇão COM O SABER}

Com efeito, Bernard Charlot, em seus estudos sobre o fracasso escolar, vem apresentando reflexões sobre o problema do conhecimento e sua distinção em relação aos saberes dos alunos. Um dos aspectos fundamentais das reflexões de Charlot (2000) é que o aluno, concebido como um sujeito do saber, não pode ser compreendido sem que se considerem suas formas específicas de relação com o mundo. Charlot reintroduz, portanto, o mundo do vivido na escola. A construção do sujeito é sempre uma relação em um mundo com os outros e, por isso, para compreender quem é o sujeito-aluno, deve-se apreender sua relação com os saberes desse mundo.

Charlot (2000, p. 80) concebe a relação com o saber como "o conjunto de imagens, de expectativas e de juízos que concernem ao mesmo tempo ao sentido e à função social do saber e da escola, à disciplina ensinada, à situação de aprendizado e a nós mesmos". A centralidade do conceito de relação é aqui fundamental, e sua articulação com o mundo, com o outro e consigo mesmo, estabelece o sentido da produção desse saber como um aprender vivido. "A relação com o saber é a relação com o mundo, com o outro e com ele mesmo, de um sujeito confrontado com a necessidade de aprender" (p. 80).

Um aspecto relevante da abordagem de Charlot (2010) é que o autor não propõe a concepção de "relação com o saber" como uma resposta que possa solucionar todos os males da educação. Antes de tudo, a "relação com o saber" seria uma forma de indagar qual a relação que o aluno tem com um saber.

Na França, já ouvi professores dizendo: ele fracassa porque não tem relação com o saber. É um erro: cada um tem uma relação com o saber, inclusive quando não gosta de estudar. É, ainda, uma catástrofe ideológica, uma vez que, ao dizer que alguém não tem uma relação com o saber, reintroduz-se a análise em termos de "carências", justamente aquela que a noção de relação com o saber permite afastar. O problema não é dizer se a relação do aluno com o saber é "boa" ou não, mas, sim, entender as contradições que o aluno enfrenta na escola. Ele vive fora da escola formas de aprender que são muito 
diferentes daquelas que o êxito escolar requer. Essas contradições é que se deve tentar entender. (CHARLOT, 2010, p. 151)

Ao ressaltar que a relação com o saber não deve ser considerada "boa" ou "má", Charlot procura evidenciar que não se trata, aqui, de determinar o que carece ao aluno. Todos os alunos têm uma relação com o saber. $\mathrm{O}$ que deve ser indagado não é o que lhe falta para um aprendizado de um conteúdo proposto, mas quais relações o aluno, como sujeito, estabelece com os saberes e por meio de que relações ele lhes atribui sentido e significado.

As proposições de Charlot (2000, 2010) possibilitam que se avance em novas direções, considerando-se que estabelecem uma distinção entre o conhecimento escolarizado e o saber, compreendido como uma forma de relação subjetiva com o mundo, consigo e com os outros. Além disso, há no pensamento de Charlot um projeto que procura interpretar a realidade por meio dos processos que a constituem no sujeito.

Aquilo que aqui se denomina como realidade não tem uma existência em si mesma, independente dos sujeitos sociais, mas é o resultado de processos subjetivos e por isso pode variar segundo a percepção individual. $O$ aluno não é passivo diante da realidade, mas é sujeito ativo de sua estruturação. Por isso, para Charlot (2000), é preciso aprender com o aluno a compreender os processos com os quais ele se defronta diante de novas formas de saber. Não se pode, simplesmente, ignorar as dificuldades enfrentadas pelos alunos e denominá-las de fracasso, mas importa, acima de tudo, indagar-se pelo que está ocorrendo. Segundo Charlot, é necessário

[...] prestar atenção também ao que as pessoas fazem, conseguem, têm e são, e não somente àquilo em que elas falham e às suas carências. É, por exemplo, perguntar-se o que sabem (apesar de tudo) os alunos em situação de fracasso - o que eles sabem da vida, mas também o que adquiriram dos conhecimentos de que a escola procura prover-lhes. (CHARLOT, 2000, p. 30)

Isso significa que o professor deve voltar-se para a esfera do vivido. Perguntar-se pelo que está ocorrendo constitui uma volta à concepção de observação e experiência como condições constituintes da vida, tanto do docente como do aluno. Observar o aluno é, assim, um processo ativo também para o professor, que encontra novas formas de estruturar o mundo e o seu conhecimento em relação aos saberes dos alunos. 
Como observa Charlot (2000), o saber se organiza no sujeito de acordo com as relações internas, por meio de sua confrontação com o mundo e com os outros. Nesse sentido, não há saber fora do âmbito social, pois, embora seja constituído como atividade, no sujeito, o saber é de natureza coletiva. É o resultado da atividade humana e se constitui por meio da relação do sujeito com o mundo e com a vida. Assim, não há saber, se ele não for confrontado com a sua construção coletiva, da mesma forma que não há saber se não existir uma relação do sujeito com o saber. Esse, segundo Charlot (2000), é o campo de possibilidades que a relação com o saber descortina para o processo educacional. Não se trata mais de uma apresentação de conteúdos validados pela ciência, mas de um processo que permita ao sujeito estabelecer uma relação de saber com o mundo.

\section{CONSIDERAÇÕES FINAIS}

A ciência moderna legou à educação uma concepção de conhecimento que afastou os sujeitos educacionais do mundo vivido. Da mesma forma que o conhecimento científico moderno acabou por separar-se da vida, também a educação se afastou do mundo vivido, tornando-se cada vez mais estranha às relações cotidianas.

Ao procurar separar-se do senso comum e das formas de saberes populares, a ciência moderna cunhou uma concepção de conhecimento cujos sentidos e significados ficaram restritos às autoridades científicas e acadêmicas. $\mathrm{O}$ mesmo processo que negou ao mundo da vida e aos saberes cotidianos o estatuto científico também excluiu todas as formas de saberes populares das escolas, e o ensino passou a dedicar-se exclusivamente ao conhecimento produzido pela ciência moderna.

Esse processo, que alienou o conhecimento científico da esfera da vida, também acabou por alienar os agentes escolares, que passaram a considerar os saberes trazidos pelos alunos e produzidos por suas comunidades como uma ausência de saber.

Nesse sentido, a contribuição de Charlot é fundamental para que se possa compreender que aquilo que se convencionou chamar de "fracasso" do aluno não pode ser concebido como uma ausência de conhecimento. Trata-se, antes, de uma incompatibilidade dos saberes produzidos pela coletividade e que constituem o mundo da vida dos alunos com um discurso científico alienado dessa realidade. A proposta de Charlot de compreender a relação com os saberes abre, assim, uma nova perspectiva para que se repense o processo educativo, restaurando, por meio da relação com o saber, a relação entre o conhecimento e a vida. 


\section{REFERÊNCIAS}

ARENDT, H. A condição humana. Tradução de Roberto Raposo. Rio de Janeiro-RJ: Forense Universitária, 2015.

ARISTÓTELES. Metafísica. São Paulo: Abril Cultural, 1978. (Coleção Os Pensadores).

CHARLOT, B. Da relação com o saber - Elementos para uma teoria. Porto Alegre: Artmed, 2000.

CHARLOT, B. Desafios da educação na contemporaneidade: reflexões de um pesquisador. Entrevista com Bernard Charlot. Educação e Pesquisa, São Paulo, v. 36, p. 133-143, 2010. Disponível em: https://doi.org/10.1590/S1517-97022010000400012.

FERREIRA, A. B. de H. et al. Novo Dicionário Aurélio da Língua Portuguesa. Rio de Janeiro: Nova Fronteira, 1986.

FOUREZ, G. A construção das ciências. São Paulo: Editora Unesp, 1995.

GARCÍA HUERTA, L. G. Conocimiento. In: CEREZO, S. S. (dir.). Diccionario de las Ciencias de la Educación, Madrid: Editorial Santillana, 1995.

HOUAISS, A.; VILLAR, M. de S.; FRANCO, F. M. de M. Dicionário Houaiss da Língua Portuguesa.

Rio de Janeiro: Objetiva, 2001.

PLATÃO. Teeteto. Rio de Janeiro: Loyola, 2020.

RISCAL, S. A. Algumas considerações sobre a escola de hoje: a indisciplina como processo educativo docente. In: RISCAL, S. A.; OLIVEIRA, B. A.; BALDAN, M. A coordenação pedagógica e a gestão democrática. São Carlos: Pixel, 2016.

\section{SOBRE OS AUTORES}

Sandra Aparecida Riscal é graduada em Pedagogia pela Universidade Estadual de Campinas - Unicamp e doutora em Educação também por esta Universidade. Atualmente é professora associada do Departamento de Educação e do Programa de Pós-Graduação em Educação da Universidade Federal de São Carlos - UFSCar. ORCID ID: https://orcid.org/oooo-0oo1-5964-3586.

E-mail: riscal@uol.com.br.

José Reinaldo Riscal é bacharel em estatística pela Universidade de São Paulo - USP, mestre em Educação pela Universidade Federal de São Carlos - UFSCar e doutor em Educação também por esta Universidade. ORCID ID: https://orcid.org/oooo-ooo1-5648-5498. E-mail: joseriscal2012@gmail.com.

Recebido em 15 de fevereiro de 2021 e aprovado em 14 de julho de 2021. 